\title{
Solar-Driven Hydrogen Peroxide Production Using Polymer- Supported Carbon Dots as Heterogeneous Catalyst
}

\author{
Satyabrat Gogoi ${ }^{1} \cdot$ Niranjan Karak $^{1}$
}

Received: 20 December 2016/ Accepted: 9 February 2017/Published online: 17 March 2017

(C) The Author(s) 2017. This article is published with open access at Springerlink.com

\section{Highlights}

- Polyurethane-supported carbon dots were developed as heterogeneous catalyst, and the developed catalyst was biodegradable.

- Solar-driven $\mathrm{H}_{2} \mathrm{O}_{2}$ production from water, ethanol, and oxygen was achieved.

\begin{abstract}
Safe, sustainable, and green production of hydro gen peroxide is an exciting proposition due to the role of hydrogen peroxide as a green oxidant and energy carrier for fuel cells. The current work reports the development of carbon dot-impregnated waterborne hyperbranched polyurethane as a heterogeneous photo-catalyst for solar-driven production of hydrogen peroxide. The results reveal that the carbon dots possess a suitable band-gap of $2.98 \mathrm{eV}$, which facilitates effective splitting of both water and ethanol under solar irradiation. Inclusion of the carbon dots within the eco-friendly polymeric material ensures their catalytic activity and also provides a facile route for easy catalyst separation, especially from a solubilizing medium. The overall process was performed in accordance with the principles of green chemistry using bio-based precursors
\end{abstract}

Electronic supplementary material The online version of this article (doi:10.1007/s40820-017-0143-7) contains supplementary material, which is available to authorized users.

Niranjan Karak

nkarak@tezu.ernet.in

1 Advanced Polymer and Nanomaterial Laboratory, Department of Chemical Sciences, Tezpur University, Tezpur 784028, Assam, India and aqueous medium. This work highlights the potential of carbon dots as an effective photo-catalyst.

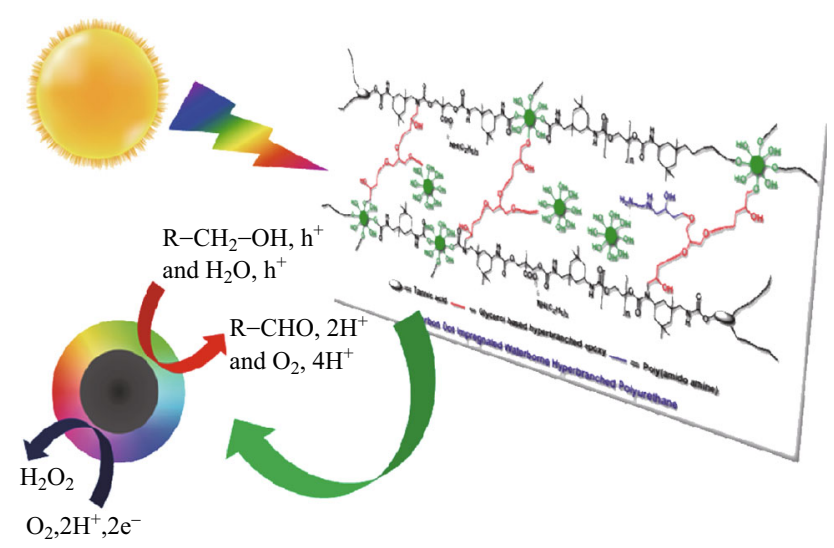

Keywords Carbon dot · Photo-catalyst - Heterogeneous catalyst · Hydrogen peroxide

\section{Introduction}

Recently, greener, inexpensive, and efficient water splitting techniques have garnered significant interest in the thrust toward sustainable energy conversion processes [1-3]. In 
this context, photo-catalysis has been adopted as a "green" and "sustainable" technique [4]. In the last few years, much effort has been devoted toward sustainable production of hydrogen peroxide $\left(\mathrm{H}_{2} \mathrm{O}_{2}\right)$ by photo-splitting of water $\left(\mathrm{H}_{2} \mathrm{O}\right)$. In the current scenario of rapid depletion of fossil fuels, sustainable production of $\mathrm{H}_{2} \mathrm{O}_{2}$ is very significant. $\mathrm{H}_{2} \mathrm{O}_{2}$ can be used as a fuel in one-compartment fuel cells with an output potential of $1.09 \mathrm{~V}$, which is comparable to that of the hydrogen fuel cell with an output value of $1.23 \mathrm{~V}$ [5]. Further, $\mathrm{H}_{2} \mathrm{O}_{2}$ serves as a clean and green oxidant with $\mathrm{H}_{2} \mathrm{O}$ as the only by-product [6]. Thus, green and sustainable production of $\mathrm{H}_{2} \mathrm{O}_{2}$ is highly desirable for implementation of "green chemistry" principles and can provide a promising prospect for resolving global fuel woes.

In the conventional process, $\mathrm{H}_{2} \mathrm{O}_{2}$ is produced by the anthraquinone method, which is highly disadvantageous from the green chemistry point of view. The drawbacks include the multi-step process, and high energy consumption, et cetera [7]. Catalytic systems such as Pd and bimetallic $\mathrm{Au}-\mathrm{Pd}$ have been studied for the direct production of $\mathrm{H}_{2} \mathrm{O}_{2}$ from $\mathrm{H}_{2}$ and $\mathrm{O}_{2}$ [8-11]. Such direct methods are effective for quantitative production of $\mathrm{H}_{2} \mathrm{O}_{2}$, but have an attendant high risk because of the explosive nature of the $\mathrm{H}_{2} / \mathrm{O}_{2}$ mixture. Most recently, semiconductor-based nanocatalysts have been used for sustainable production of $\mathrm{H}_{2} \mathrm{O}_{2}$ from $\mathrm{H}_{2} \mathrm{O}$ and alcohols. Such methods involve irradiation of an oxygen $\left(\mathrm{O}_{2}\right)$-saturated alcohol or aqueous system under UV light in the presence of metallic semiconductors. State-of-the-art literature cites the use of different metal-based semi-conductor catalysts for sustainable production of $\mathrm{H}_{2} \mathrm{O}_{2}$ from $\mathrm{H}_{2} \mathrm{O}$ and alcohol. These include $\mathrm{Ru}$-complexes, Ir-complexes, $\mathrm{Ti}$ nanoparticles, and $\mathrm{Ni}$, et cetera [12-20]. However, the major concerns associated with these catalysts are their high cost, toxicity, metalbased origin, and non-degradable nature. In an effort to introduce metal-free and degradable catalysts, Shiraishi and his group reported polymeric graphitic carbon nitride ( $\left.g-\mathrm{C}_{3} \mathrm{~N}_{4}\right)$ for the production of $\mathrm{H}_{2} \mathrm{O}_{2}$ from ethanol [21]. However, the high production cost and low band-gap of $g$ $\mathrm{C}_{3} \mathrm{~N}_{4}$ hamper its successful use, especially for splitting $\mathrm{H}_{2} \mathrm{O}$ under solar irradiation. Thus, the development of an eco-friendly and sustainable catalyst system with the capacity to produce $\mathrm{H}_{2} \mathrm{O}_{2}$ is desirable to meet the current challenges.

Carbon dots (CDs), with unique physical, chemical, and optical properties, have attracted immense interest in the scientific community based on their utility in diverse areas, such as bio-imaging, biosensors, light-emitting diodes, and other opto-electrical devices [22-25]. The unique traits of CDs include their excitation wavelength-dependent stable multi-color emission and excellent aqueous solubility with remarkable cytocompatibility. Like other quantum dots, exhibition of the "quantum confinement" effect is the typical signature of CDs. CDs consist predominantly of amorphous carbon along with $s p^{2}$ hybridized graphitic carbon. The most fascinating feature of $\mathrm{CDs}$ is their capability to harvest photons in the UV/visible spectral region. Such light-harvesting ability renders CDs as a potential candidate for photo-catalytic application [1, 26]. However, in practice, there are certain difficulties in the use of bare CDs as an effective photo-catalyst. CDs are soluble in water or organic solvents like ethanol. This creates serious difficulties in their separation when such media are used. However, in media where CDs are insoluble, CDs suffer solid-state quenching of the photo-activity [27]. Such obstacles restrict the practical applicability of CDs as photo-catalysts.

In this context, the use of a polymeric matrix as a support can facilitate the application of CDs. The polymer matrix can prevent solid-state quenching and also provide sufficient mechanical strength and catalytic stability and facilitate application with easy separation. Such polymer/ CD nanocomposite systems have found use in opto-electrical applications. Photo-catalytic applications have also been reported recently [28]. In this regard, we found that the waterborne hyperbranched polyurethane (WPU) system is attractive as a polymer support. The solubility of both the nanomaterial and polymer in the same medium (aqueous) expedites homogeneous distribution of the CDs over the polymer matrix, thereby preserving their photo-harvesting ability. Further, the use of WPU offers additional advantages. During the polymerization reaction, WPU becomes soluble due to the creation of ionic centers along the polymer chains. Thus, it behaves like an ionomer with electron transfer capability. Hence, compared to conventional polymeric systems, WPU is expected to act as a better catalyst support for photo-catalytic reactions.

Herein, a CD-impregnated WPU nanocomposite film is used as a heterogeneous photo-catalyst for solar-driven production of $\mathrm{H}_{2} \mathrm{O}_{2}$ by using $\mathrm{H}_{2} \mathrm{O}, \mathrm{C}_{2} \mathrm{H}_{5} \mathrm{OH}$, and $\mathrm{O}_{2}$ as raw materials. Further, bacterial degradation of the catalyst is carried out by using Pseudomonas aeruginosa to highlight its eco-friendly behavior. Thus, the present study reports a metal-free, low-cost, easily separable, non-toxic, and biodegradable carbon dot-impregnated polymeric nanocomposite system as a heterogeneous catalyst for sustainable and green production of $\mathrm{H}_{2} \mathrm{O}_{2}$.

\section{Experimental}

\subsection{Materials}

Isophorone diisocyanate (IPDI, Aldrich, Germany), poly(ethylene glycol) with a number average molecular weight 
$\left(M_{n}\right)$ of $600 \mathrm{~g} \mathrm{~mol}^{-1}$ (PEG 600, Merck, India), 2,2bis(hydroxymethyl) propionic acid (BMPA, Aldrich, Germany), 1,4-butanediol (BD, Merck, India), tannic acid (TA, Sigma-Aldrich, Belgium), triethylamine (TEA, Merck, India), and tetrahydrofuran (THF, Merck, India) were used for WPU preparation. Glycerol-based hyperbranched epoxy (HE) and vegetable oil-based poly(amide amine) (PAA) were used to cross-link the fabricated WPU/CD system [29, 30]. Corms of Colocasia esculenta were used to prepare the CDs. Moreover, ethanol $\left(\mathrm{C}_{2} \mathrm{H}_{5} \mathrm{OH}\right.$, Merck, India), Millipore water $\left(\mathrm{H}_{2} \mathrm{O}\right.$, obtained from MilliQ ${ }^{\circledR}$ Ultrapure Water Solutions, Type 1, water purifier system), and oxygen $\left(\mathrm{O}_{2}\right.$, obtained from Jainex Gas Company, India) were used as starting materials in the photo-catalytic application. Potassium permanganate $\left(\mathrm{KMnO}_{4}\right.$, Merck, India) was used in the estimation of hydrogen peroxide by following a titrimetric method. In the biodegradation study, the bacterial strain Pseudomonas aeruginosa (strain MTCC 7814) was used. This strain was procured from the Microbial Type Culture Collection and Gene Bank, Chandigarh, India. The bacterial culture was collected through the Department of Molecular Biology and Biotechnology, Tezpur University, India.

\subsection{Catalyst Preparation}

The CDs were prepared by using corms of $C$. esculenta as reported earlier [31]. However, a slight modification was made to the synthetic procedure. In order to exert greater control over the particle size and size distribution, a hydrothermal method was employed. Briefly, an aqueous extract $(100 \mathrm{~mL})$ of corms of $C$. esculenta was heated at $150{ }^{\circ} \mathrm{C}$ for $5 \mathrm{~h}$ in a Teflon-lined hydrothermal reactor (250 mL capacity). The CDs formed were dried under reduced pressure. The CD-impregnated WPU polymer was prepared via an ex situ technique according to a method described elsewhere [31]. However, in the present study, we used a high $\mathrm{CD}$ loading compared to that previously reported. Briefly, IPDI, PEG 600, and BD were reacted in the pre-polymerization step at a temperature of $85 \pm 2{ }^{\circ} \mathrm{C}$. In the next step, TA and BD were allowed to react with the pre-polymer formed in the first step at $70 \pm 2{ }^{\circ} \mathrm{C}$ for 4-4.5 h. This process was followed by neutralization using TEA at room temperature. Finally, water was added and THF was removed under reduced pressure. Different weight percentages of $\mathrm{CD}$ were incorporated into the WPU matrix by using mechanical and ultra-sound energy. These nanocomposites were coded as PNC1.0, PNC2.0, PNC3.0, PNC4.0, and PNC5.0 for CD loadings of $1,2,3,4$, and $5 \mathrm{wt} \%$, respectively. Further, the nanocomposites were cross-linked by using HE and PAA. Details of the fabrication technique are provided in Supplementary Information.

\subsection{Catalyst Characterization}

X-ray diffraction (XRD) patterns of the CDs and CD-impregnated WPU were obtained by using a Bruker AXS, Germany, Model: D8 Focus instrument $\left(2 \theta=10^{\circ}-70^{\circ}\right.$ at a scanning rate of $2^{\circ} \mathrm{min}^{-1}$ ). The graphitic structure of the CDs was studied using Raman spectroscopy (Renishaw, UK, Renishaw Basis Series with 514 nm Laser). The shape and size of the CDs, as well as the distribution of the CDs over the WPU matrix, were visually studied by using highresolution transmission electron microscopic (HRTEM) analysis. TEM images were obtained by using a JEOL, JEMCXII, Japan, microscope at an operating voltage of $200 \mathrm{kV}$ using a $\mathrm{Cu}$ grid (TED PELLA INC, Ultrathin C, Type A, 400 mesh). The microscopic data were analyzed as inverse fast Fourier transform (IFFT) images by using Gatan Digital Micrograph software. A UV-visible photospectrometer (Thermo-Scientific, Evolve 300, USA) was used to determine the band-gap. The photoluminescence (PL) behavior was studied by using a PerkinElmer, USA, Model: LS-55 fluorescence spectrometer. The surface morphology of the biodegraded catalyst was studied by scanning electron microscopy (SEM, JEOL, JSM 6390LV) after platinum coating the surface.

\subsection{Band-Gap}

The band-gap of the CDs was evaluated by using UVvisible spectroscopy and applying Eq. 1 [32],

$\alpha=C\left(h v-E_{\text {bulk }}\right)^{1 / 2} / h v$

Here $\alpha$ is the absorption coefficient, $C$ is a constant, $\mathrm{h}$ is Plank's constant, $v$ is the frequency, and $E_{\text {bulk }}$ is the energy gap. In practice, the band-gap is calculated by plotting $\mathrm{h} v$ versus $(\alpha \mathrm{h} v)^{2}$. Extrapolation of the curve to $(\alpha \mathrm{h} v)^{2}$ gives the value of $E_{\text {bulk }}$.

\subsection{Determination of Quantum Yield}

The quantum yield of the CDs and PNCs was determined by using Eq. 2 [33].

$Q_{\mathrm{CD}}=Q_{\mathrm{R}} \frac{I_{\mathrm{CD}} \cdot A_{\mathrm{R}} \cdot \eta_{\mathrm{CD}}^{2}}{I_{\mathrm{R}} \cdot A_{\mathrm{CD}} \cdot \eta_{\mathrm{R}}^{2}}$

Here, $Q_{\mathrm{CD}}$ is the quantum yield of the CDs, $Q_{\mathrm{R}}$ is the quantum yield of the reference compound (quinine sulfate), $I_{\mathrm{CD}}$ is the intensity of the emission of the CDs, $I_{\mathrm{R}}$ is the intensity of the luminescence of the reference compound (quinine sulfate), $A_{\mathrm{CD}}$ is the absorbance of the CDs at the given excitation wavelength $(360 \mathrm{~nm}), A_{\mathrm{R}}$ is the absorbance of the reference compound (quinine sulfate) at the given excitation wavelength $(360 \mathrm{~nm})$, and $\eta$ is the 
refractive index of the solvent used (water). The quantum yield of quinine sulfate at $360 \mathrm{~nm}$ is $54 \%$.

\subsection{Photo-catalytic Reaction}

Five different compositions, i.e., $\mathrm{H}_{2} \mathrm{O}, \mathrm{C}_{2} \mathrm{H}_{5} \mathrm{OH}(100 \%)$, and mixtures of $\mathrm{H}_{2} \mathrm{O}$ and $\mathrm{C}_{2} \mathrm{H}_{5} \mathrm{OH}(25,50$, and $75 \%$ (v/v)) were used as the starting materials for the solar-driven production of $\mathrm{H}_{2} \mathrm{O}_{2}$. The reactants were placed into a twonecked glass reactor equipped with an $\mathrm{O}_{2}$ inlet. Initially, the mixture was saturated with molecular $\mathrm{O}_{2}$ by passing the gas for $10 \mathrm{~min}$ and the reactor was then sealed. The system was then irradiated under normal solar light with an intensity of $80,000-100,000 \mathrm{~lx}$ at ca. $25^{\circ} \mathrm{C}$ with a continuous supply of $\mathrm{O}_{2}$ for different time intervals $(5-50 \mathrm{~h})$. The production of $\mathrm{H}_{2} \mathrm{O}_{2}$ was estimated via the redox titrimetric method using $\mathrm{KMnO}_{4}$ [23].

\subsection{Biodegradation Study}

Analysis of the biodegradability of the catalyst system was carried out by using $P$. aeruginosa as the test organism [34]. A mineral salt solution containing $2.0 \mathrm{~g}\left(\mathrm{NH}_{4}\right)_{2} \mathrm{SO}_{4}$, $2.0 \mathrm{~g} \mathrm{Na} \mathrm{HPO}_{4}, 4.75 \mathrm{~g} \quad \mathrm{KH}_{2} \mathrm{PO}_{4}, 1.2 \mathrm{~g} \mathrm{MgSO}_{4} \cdot 7 \mathrm{H}_{2} \mathrm{O}$, $0.5 \mathrm{mg} \quad \mathrm{CaCl}_{2} \cdot 2 \mathrm{H}_{2} \mathrm{O}, 100 \mathrm{mg} \quad \mathrm{MnSO}_{4} \cdot 5 \mathrm{H}_{2} \mathrm{O}, \quad 70 \mathrm{mg}$ $\mathrm{ZnSO}_{4} \cdot 7 \mathrm{H}_{2} \mathrm{O}, 10 \mathrm{mg} \mathrm{H} \mathrm{BO}_{3} \cdot 5 \mathrm{H}_{2} \mathrm{O}, 100 \mathrm{mg} \mathrm{CuSO} \cdot 7 \mathrm{H}_{2} \mathrm{O}$, $1 \mathrm{mg} \mathrm{FeSO} \cdot 7 \mathrm{H}_{2} \mathrm{O}$, and $10 \mathrm{mg} \mathrm{MoO}_{3}$ in $1000 \mathrm{~mL}$ distilled water was prepared and sterilized at $120^{\circ} \mathrm{C}$ under $15 \mathrm{lb}$ pressure. The $P$. aeruginosa bacterial strain was cultured in a shaker incubator for $48 \mathrm{~h}$ using this medium. A $100-\mu \mathrm{L}$ aliquot of the cultured bacteria was placed in a conical flask with $10 \mathrm{~mL}$ of the salt medium. UV-sterilized (wavelength $254 \mathrm{~nm}$ ) catalyst films with a known weight were immersed in the medium and incubated at $37^{\circ} \mathrm{C}$ for seven weeks. Growth of the bacteria was followed by measuring the absorbance of the medium at $600 \mathrm{~nm}$ at an interval of seven days. Similarly, a change in the weight of the catalyst was recorded after every seven days. SEM images of the biodegraded films were also taken after completion of the experimental period.

\section{Results and Discussion}

The synthesis of the CDs provides a green and sustainable route in which a large number of naturally available carbon resources are utilized [35]. In the present study, a carbohydrate-rich aqueous extract of corms of $C$. esculenta was used as the precursor. The CDs were obtained through a hydrothermal method. It can be assumed that in the hydrothermal process, extensive carbonization and aromatization took place through condensation and polymerization of different carbohydrate molecules at elevated temperature and pressure $[33,36]$.

The prepared CDs were characterized by TEM, XRD, and Raman spectroscopic techniques. As shown in Fig. 1a, $b$, the TEM image of the CDs indicates the formation of carbon nanoparticles with nearly spherical morphology. Statistical evaluation of the size distribution revealed that the size of the CDs ranged from 1.5 to $3.5 \mathrm{~nm}$. The majority of the CDs has sizes in the range of 1.7-2.1 nm (see Fig. 1g). Compared to the simple heating process (at $150{ }^{\circ} \mathrm{C}$ for $3.5 \mathrm{~h}$ ) reported previously by the same group, the size distribution was found to be restricted within a narrow range and with a smaller diameter [31]. Controlling the size of the CDs is important because the size can influence the bandgap, which is a critical parameter for water splitting.

Figure 1c shows the IFFT image of the CDs, indicating a layer spacing of $0.39 \mathrm{~nm}$, which can be assigned to the (022) graphitic plane of the CDs. However, compared to the inter-planar distance of the pure graphitic structure ( $\sim 0.34 \mathrm{~nm}$ ), the spacing was greater in the case of the CDs. This may be ascribed to the presence of oxygeneous functionalities in the $\mathrm{CD}$ structure, which are intercalated between the consecutive layers, leading to a larger interplanar seperation. In comparison, the XRD pattern of the CDs displayed a broad peak centered around $2 \theta=22^{\circ}$ (Fig. 2a). This is characteristic of a weakly crystalline graphitic structure with a large number of defect sites [33].

The Raman spectrum of the CDs displayed two distinct bands, i.e., the $D$ band near $1360 \mathrm{~cm}^{-1}$ and the $\mathrm{G}$ band near $1580 \mathrm{~cm}^{-1}$ (Fig. 2b). The D band is characteristic of structural defects, and the $\mathrm{G}$ band is characteristic of symmetric $s p^{2}$ graphitic carbon stretching. UV-visible spectroscopy shows a peak near $270 \mathrm{~nm}$, which is an indication of successful formation of the CDs (Fig. S1). Thus, TEM, XRD, Raman, and UV-visible spectroscopic analyses confirmed formation of the CDs. The CDs were incorporated into the WPU matrix for the development of a heterogeneous catalyst system for solar-driven $\mathrm{H}_{2} \mathrm{O}_{2}$ production.

In this context, the critical issue is to obtain a homogeneous distribution of the CDs over the WPU matrix without agglomeration. Agglomeration of the CDs can lead to the loss of their light-absorbing capability, which in turn hampers their photo-catalytic activity. However, in the present study, we found that the CDs and WPU acted complementarily to produce a compatible and uniform composite system. The CDs, being a highly functional nanomaterial, undergo sufficient interactions (both covalent and non-covalent) with the hyperbranched polymer matrix (Fig. 3). Such prominent interactions, along with the dispersibility of both the polymer and the nanomaterial in the reaction medium, helped to produce a homogeneous polymer-supported nanosystem without any agglomeration. 

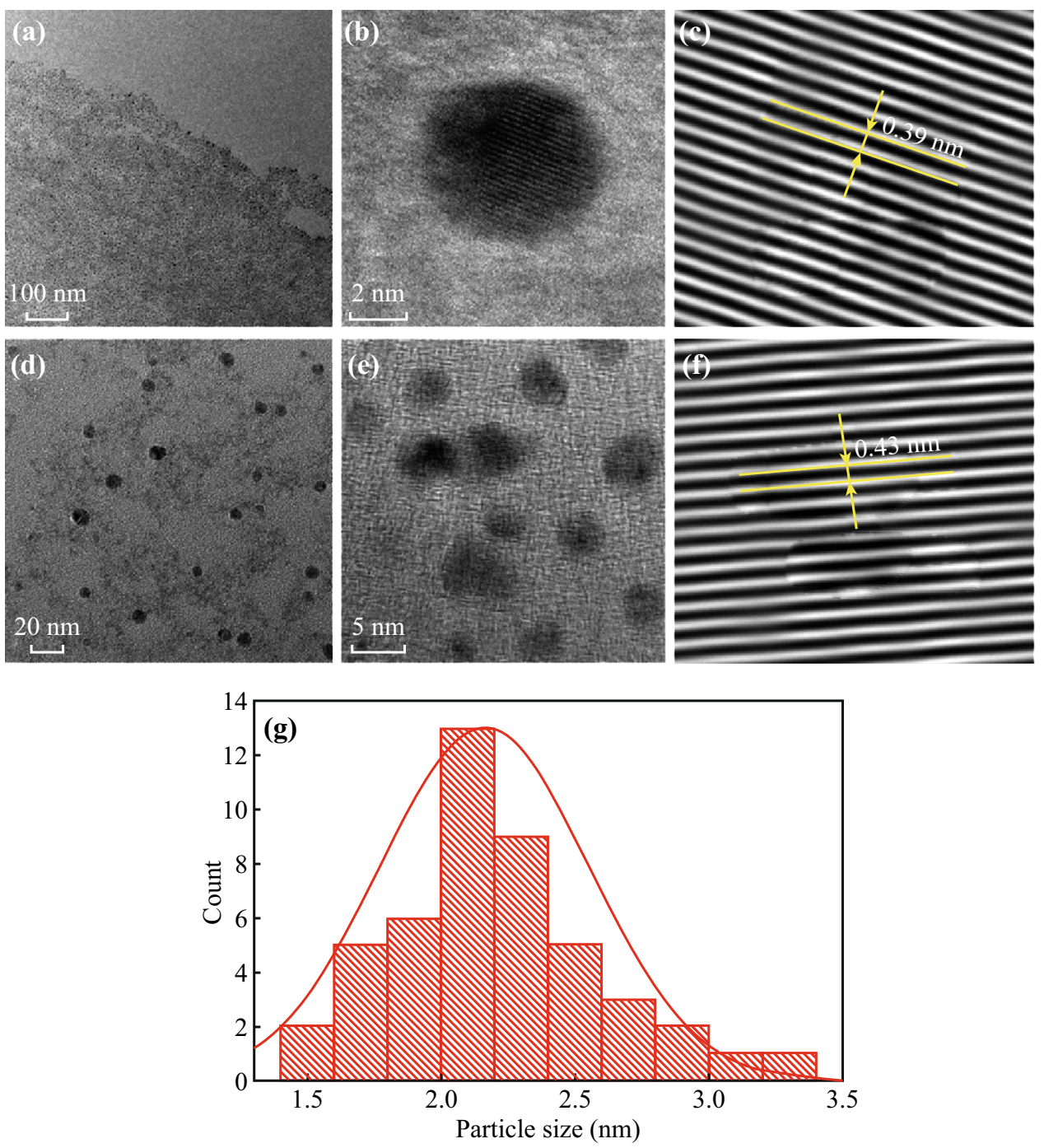

Fig. 1 a TEM image of CD. b HRTEM of CD. c IFFT image of CD. d TEM image of PNC4.0. e HRTEM of PNC4.0. $\mathbf{f}$ IFFT of PNC4.0. $\mathbf{g}$ Size distribution of CDs
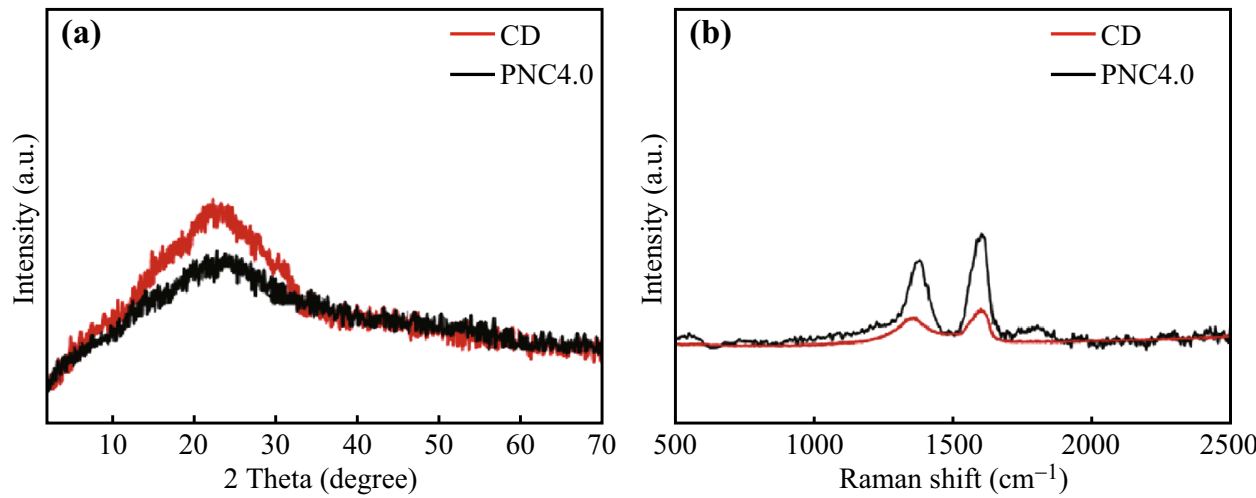

Fig. 2 a XRD patterns and b Raman spectra of CDs and PNC4.0

Visual evidence obtained from the TEM image of the catalyst system confirmed the uniformity, even at high nanomaterial loading (4 wt\%) (Fig. 1d). Comparison of the
HRTEM images (Fig. 1b, e) and corresponding IFFT images of the CDs and PNC4.0 (Fig. 1c, f) revealed an increase in the interlayer spacing from $0.39 \mathrm{~nm}$ for the 


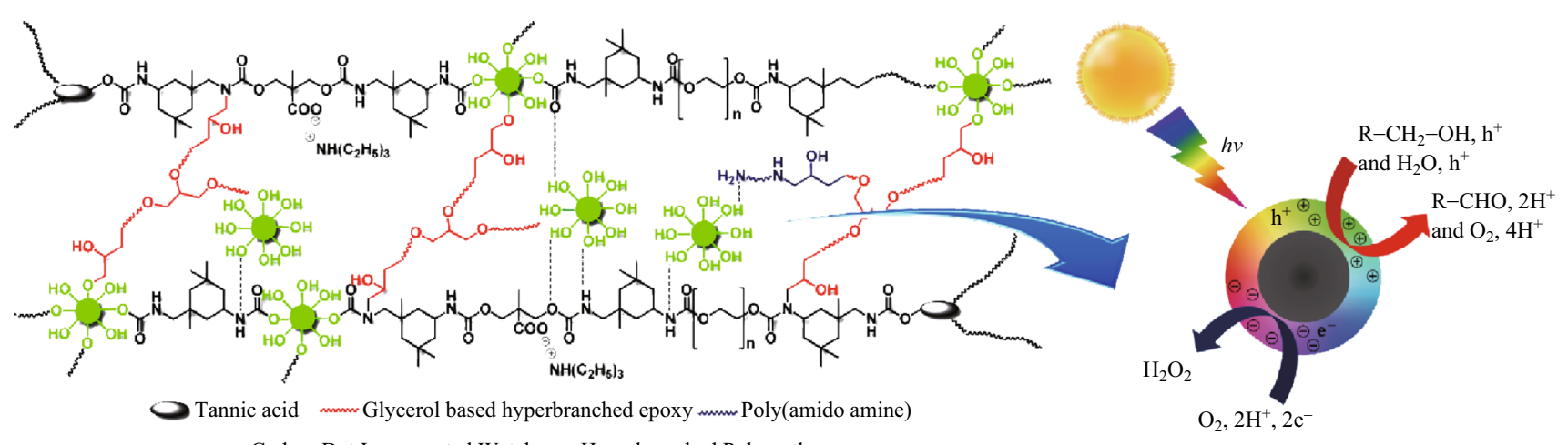

Carbon Dot Impregnated Wateborne Hyperbranched Polyurethane

Fig. 3 Solar-driven $\mathrm{H}_{2} \mathrm{O}_{2}$ production using CD-impregnated waterborne hyperbranched polyurethane as heterogeneous catalyst

pristine CDs to $0.43 \mathrm{~nm}$ after incorporation into the polymer matrix. This may be due to the additional defects created within the $\mathrm{CD}$ structure during the fabrication process. Intercalation of the polymeric chains may also increase the interlayer distance. This indicates strong interaction between the polymer and nanomaterial.

The XRD pattern of PNC4.0 showed a peak corresponding to amorphous carbon near $2 \theta=22^{\circ}$, ascribed to the (002) plane of graphitic carbon (Fig. 2a). Similar to the profile of the CDs, the Raman spectrum of PNC4.0 displayed $\mathrm{D}$ and $\mathrm{G}$ bands, albeit with a higher $I_{\mathrm{D}} / I_{\mathrm{G}}$ ratio. This provides evidence of the generation of defects in the CDs during the fabrication process. On the other hand, modification of this system with HE and PAA is expected to provide better catalyst stability and prevent $\mathrm{CD}$ leaching by the formation of a cross-linked network structure.

Before studying the photo-catalytic activity of the prepared catalyst, effort was made to evaluate different parameters, which ensured suitability of the polymer-supported CD system as a photo-catalyst for $\mathrm{H}_{2} \mathrm{O}$ splitting. By virtue of their quantum dimension, the CDs possess the capability to harvest photons over the solar spectrum (covering the entire UV-visible spectral region, extending to the near IR) based on their photo-excited states [1]. The associated transient species are responsible for the bright fluorescence as well as the redox processes, which are desirable for energy conversion applications [37, 38]. However, a precise mechanistic pathway to account for the light-harvesting capability of the CDs is yet to be established. Nevertheless, recent research gives the impression of charge separation in the form of holes (radical cation) and electrons (radical anion) via photo-excitation of the core carbon nanoparticles of the CDs. The radiative recombination of these holes and electrons, which are trapped at various surface sites, results in the observed fluorescence emission [26]. Hence, to study the light-harvesting activity of the $\mathrm{CDs}$, the photoluminescence behavior and HOMO-LUMO band-gap were evaluated.
Like the signature behavior of other quantum dots, the CDs also exhibit excitation wavelength-dependent PL behavior (Fig. S2). Considering quinine sulfate as the reference, the quantum yield was calculated at the excitation wavelength of $360 \mathrm{~nm}$ and was found to be $9.5 \%$. Values of 5.5, 6.7, 7.4, 7.8, and 7.6\% were obtained for PNC1.0, PNC2.0, PNC3.0, PNC4.0, and PNC5.0, respectively. The band-gap was calculated from UV-visible spectroscopy by plotting $h v$ versus $(\alpha \mathrm{h} v)^{2}$ (Tauc's method) and was found to be $2.98 \mathrm{eV}$ (Fig. 4). Here, it is pertinent to mention that the band-gap of carbon dots depends on the size and surface state of the nanoparticles, and the calculated value agreed with the literature data [39].

Generally, $\mathrm{H}_{2} \mathrm{O}$ splitting requires the bottom level of the conduction band to be more negative than the redox potential of $\mathrm{H}^{+} / \mathrm{H}_{2}(0 \mathrm{~V}$ vs. NHE), while the top level of the valence band should be more positive than the redox potential of $\mathrm{H}_{2} \mathrm{O} / \mathrm{O}_{2}$ (1.23 V vs. NHE). Thus, the minimum value of $E_{\text {bulk }}$ for any photo-catalyst should be $1.23 \mathrm{eV}$ for $\mathrm{H}_{2} \mathrm{O}$ splitting. However, in practice, for effective $\mathrm{H}_{2} \mathrm{O}$ splitting, the band-gap should be larger than $2.0 \mathrm{eV}$. This is

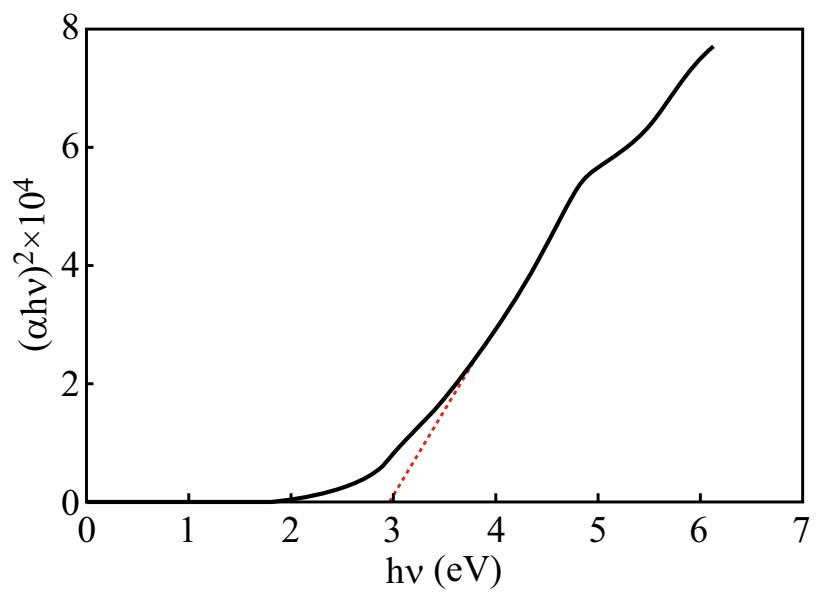

Fig. 4 Plot of $(\alpha h v)^{2}$ versus $h v$ 
because, in reality, energy losses may occur due to kinetic overpotentials.

In the present study, $E_{\text {bulk }}$ was evaluated as $2.98 \mathrm{eV}$ for the CDs. Hence, these species satisfy the criteria to act as a catalyst for solar-driven production of $\mathrm{H}_{2} \mathrm{O}_{2}$. In this context, the CDs appear to be the superior catalyst compared to $g-\mathrm{C}_{3} \mathrm{~N}_{4}$. This may be because, $g-\mathrm{C}_{3} \mathrm{~N}_{4}$ has a band-gap of $1.4 \mathrm{eV}$, which is good enough to split alcohols but is insufficient to split $\mathrm{H}_{2} \mathrm{O}$ under solar irradiation. The photocatalytic production of $\mathrm{H}_{2} \mathrm{O}_{2}$ involves photo-irradiation of $\mathrm{O}_{2}$-saturated $\mathrm{H}_{2} \mathrm{O}$ or alcohol in the presence of a photocatalyst, i.e., the CDs in the present case.

Semiconductors can act as photo-catalysts for light-induced redox processes due to their electronic structure, which is characterized by a filled valence band and an empty conduction band. Absorption of a photon with energy greater than the band-gap energy leads to the formation of an electron/hole pair. In the absence of suitable scavengers, the stored energy is dissipated within a few nanoseconds by recombination. A plausible mechanistic framework involves the formation of an electron $\left(\mathrm{e}^{-}\right) /$hole $\left(h^{+}\right)$pair by photo-excitation of the CDs. In the case of an alcohol, $\mathrm{h}^{+}$oxidizes the $\mathrm{RCH}_{2} \mathrm{OH}$ to generate aldehydes and a proton, while $\mathrm{e}^{-}$promotes two-electron reduction of $\mathrm{O}_{2}$ to produce $\mathrm{H}_{2} \mathrm{O}_{2}[6,21]$.

$\mathrm{CD} \rightarrow \mathrm{e}^{-}+h^{+}$

$\mathrm{R}-\mathrm{CH}_{2}-\mathrm{OH}+h^{+}=\mathrm{R}-\mathrm{CHO}+2 \mathrm{H}^{+}$

$\mathrm{O}_{2}+2 \mathrm{H}^{+}+2 \mathrm{e}^{-}=\mathrm{H}_{2} \mathrm{O}_{2}$

When $\mathrm{H}_{2} \mathrm{O}$ is used as the raw material, $\mathrm{h}^{+}$oxidizes $\mathrm{H}_{2} \mathrm{O}$ to $\mathrm{O}_{2}$. Similar two-electron reduction of $\mathrm{O}_{2}$ follows thereafter to produce $\mathrm{H}_{2} \mathrm{O}_{2}$ [21].

$\mathrm{CD} \rightarrow \mathrm{e}^{-}+h^{+}$

$2 \mathrm{H}_{2} \mathrm{O}+h^{+}=\mathrm{O}_{2}+4 \mathrm{H}^{+}$

$\mathrm{O}_{2}+2 \mathrm{H}^{+}+2 \mathrm{e}^{-}=\mathrm{H}_{2} \mathrm{O}_{2}$

In the current study, we used $\mathrm{H}_{2} \mathrm{O}$, mixtures of $\mathrm{H}_{2} \mathrm{O}$ and $\mathrm{C}_{2} \mathrm{H}_{5} \mathrm{OH}(25 \%, 50 \%$, and $75 \% \mathrm{v} / \mathrm{v})$, and $\mathrm{C}_{2} \mathrm{H}_{5} \mathrm{OH}(100 \%)$ saturated with molecular $\mathrm{O}_{2}$. In this regard, it is important to mention that many of the traditionally used semiconductors absorb only light energy or mostly in the UV region; hence, for a solar-driven process, dye sensitization is required [1]. However, the CDs can also absorb photons in the visible region; hence, the CDs can be readily used under sunlight. In the actual reaction setup, the reaction mixtures were irradiated under normal solar light with an intensity of $80,000-100,000 \mathrm{~lx}$ at ca. $25^{\circ} \mathrm{C}$ for different durations.

Figure 5 shows the formation of $\mathrm{H}_{2} \mathrm{O}_{2}$ at different intervals using different compositions of starting materials with PNC4.0 as the photo-catalyst. The bar diagram reveals

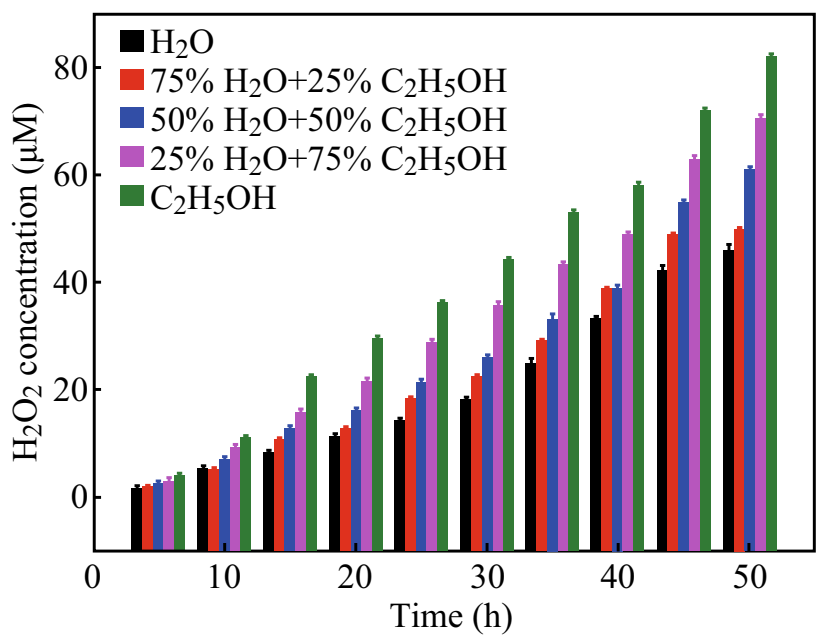

Fig. $5 \mathrm{H}_{2} \mathrm{O}_{2}$ production with different raw materials at different time intervals using PNC4.0 as catalyst

the influence of the time and the composition of the starting materials on the production of $\mathrm{H}_{2} \mathrm{O}_{2}$. The formation of $\mathrm{H}_{2} \mathrm{O}_{2}$ increased with time for the photo-reaction. Here, it is pertinent to mention that the virtual yield of $\mathrm{H}_{2} \mathrm{O}_{2}$ shown in the bar diagram might be less than the actual amount formed, as some amount of $\mathrm{H}_{2} \mathrm{O}_{2}$ is destroyed by sunlight.

Nevertheless, the increased production of $\mathrm{H}_{2} \mathrm{O}_{2}$ with time clearly indicates the efficiency of the polymer-supported CDs as a photo-catalyst in the $\mathrm{H}_{2} \mathrm{O}$ splitting reaction. The rate of formation of $\mathrm{H}_{2} \mathrm{O}_{2}$ also supports this claim (Fig. S3). Some interesting observations emerge from this study. When $\mathrm{H}_{2} \mathrm{O}$ was used by itself, less $\mathrm{H}_{2} \mathrm{O}_{2}$ was produced ( $\sim 46 \mu \mathrm{M}$ after $50 \mathrm{~h}$ of reaction) compared to that obtained with $100 \% \mathrm{C}_{2} \mathrm{H}_{5} \mathrm{OH}(\sim 82 \mu \mathrm{M})$. On the other hand, in the case of the $\mathrm{C}_{2} \mathrm{H}_{5} \mathrm{OH} / \mathrm{H}_{2} \mathrm{O}$ mixtures, the $\mathrm{H}_{2} \mathrm{O}_{2}$ production increased with an increase in the amount of $\mathrm{C}_{2} \mathrm{H}_{5} \mathrm{OH}$ in the mixture $\left(\sim 49 \mu \mathrm{M}\right.$ for $25 \% \mathrm{C}_{2} \mathrm{H}_{5} \mathrm{OH} /$ $75 \% \mathrm{H}_{2} \mathrm{O}, \sim 61 \mu \mathrm{M}$ for $50 \% \mathrm{C}_{2} \mathrm{H}_{5} \mathrm{OH} / 50 \% \mathrm{H}_{2} \mathrm{O}$, and $\sim 70 \mu \mathrm{M}$ for $75 \% \mathrm{C}_{2} \mathrm{H}_{5} \mathrm{OH} / 25 \% \mathrm{H}_{2} \mathrm{O}$ ). The increased $\mathrm{H}_{2} \mathrm{O}_{2}$ production in the presence of $\mathrm{C}_{2} \mathrm{H}_{5} \mathrm{OH}$ may be because of the favorable thermodynamic driving force, which is promoted by the suitable oxidation and reduction potential of the catalyst when alcohol is used (compared to water) [6]. A previous report also suggests similar behavior of alcohol and $\mathrm{H}_{2} \mathrm{O}$ mixtures toward solar-driven water splitting [21]. Thus, these data suggest that the photo-reaction of $\mathrm{H}_{2} \mathrm{O}$ with $\mathrm{C}_{2} \mathrm{H}_{5} \mathrm{OH}$ can enhance the $\mathrm{H}_{2} \mathrm{O}_{2}$ yield.

Figure 6 shows the selectivity toward $\mathrm{H}_{2} \mathrm{O}_{2}$ production when different compositions of starting materials were used. When $\mathrm{H}_{2} \mathrm{O}$ was used as the starting material, $100 \%$ selectivity for the production of $\mathrm{H}_{2} \mathrm{O}_{2}$ was achieved. However, when $\mathrm{C}_{2} \mathrm{H}_{5} \mathrm{OH}$ was used, the reaction showed no selectivity. Along with $\mathrm{H}_{2} \mathrm{O}_{2}$, a mixture of acetaldehyde and acetic acid was also formed, in which acetaldehyde was the predominant product, as confirmed by GC analysis. 


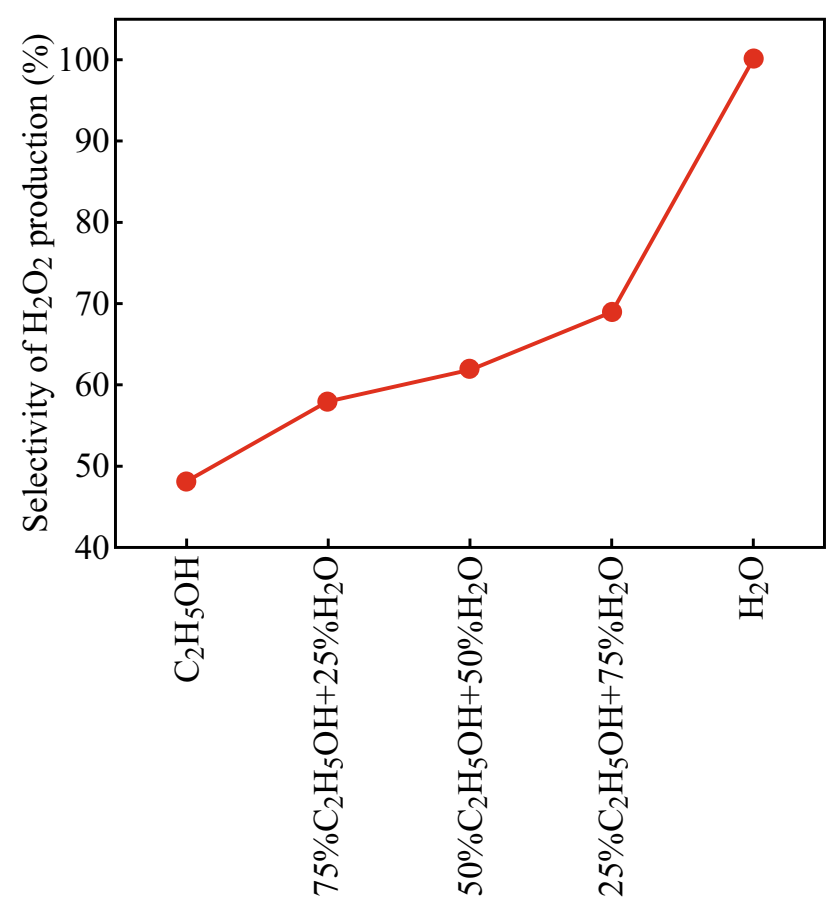

Fig. 6 Selectivity curve for $\mathrm{H}_{2} \mathrm{O}_{2}$ production with different starting materials (using PNC4.0 as catalyst)

With an increase in the $\mathrm{H}_{2} \mathrm{O}$ gradient in the mixtures of $\mathrm{C}_{2} \mathrm{H}_{5} \mathrm{OH} / \mathrm{H}_{2} \mathrm{O}$, the selectivity toward $\mathrm{H}_{2} \mathrm{O}_{2}$ production also increased $\left(\sim 48 \%\right.$ when only $\mathrm{C}_{2} \mathrm{H}_{5} \mathrm{OH}$ was used, $\sim 58 \%$ for $75 \% \mathrm{C}_{2} \mathrm{H}_{5} \mathrm{OH} / 25 \% \mathrm{H}_{2} \mathrm{O}, \sim 62 \%$ for $50 \% \mathrm{C}_{2} \mathrm{H}_{5} \mathrm{OH} /$ $50 \% \mathrm{H}_{2} \mathrm{O}, \sim 69 \%$ for $25 \% \mathrm{C}_{2} \mathrm{H}_{5} \mathrm{OH} / 75 \% \mathrm{H}_{2} \mathrm{O}$, and $100 \%$ for $\mathrm{H}_{2} \mathrm{O}$ only). In other words, the production of $\mathrm{H}_{2} \mathrm{O}_{2}$ increased with respect to the by-products. This clearly suggests that the two-electron reduction of oxygen loses its selectivity when $\mathrm{C}_{2} \mathrm{H}_{5} \mathrm{OH}$ is used, whereas addition of $\mathrm{H}_{2} \mathrm{O}$ enhances the selectivity. Thus, it can be inferred that photoreaction of $\mathrm{C}_{2} \mathrm{H}_{5} \mathrm{OH}$ with $\mathrm{H}_{2} \mathrm{O}$ around room temperature promotes selective $\mathrm{H}_{2} \mathrm{O}_{2}$ production.

The influence of the $\mathrm{CD}$ loading on $\mathrm{H}_{2} \mathrm{O}_{2}$ generation was evaluated (Fig. 7). In $50 \mathrm{~h}$ of photo-reaction, the production of $\mathrm{H}_{2} \mathrm{O}_{2}$ increased with an increase in the $\mathrm{CD}$ content up to $4 \mathrm{wt} \%$. However, from a loading of $5 \mathrm{wt} \%$ onwards, the production of $\mathrm{H}_{2} \mathrm{O}_{2}$ declined slightly. This may be because of agglomeration of the CDs at higher loading, which reduces their light-harvesting ability. The quantum yields of the PNCs also supported this claim. PNC4.0 was found to have the optimal composition for $\mathrm{H}_{2} \mathrm{O}_{2}$ production via the photo-splitting of $\mathrm{H}_{2} \mathrm{O}$ and $\mathrm{C}_{2} \mathrm{H}_{5} \mathrm{OH}$.

Here, it is pertinent to mention that $\mathrm{CD}$ alone can act as an effective catalyst with higher production yield (Fig. S4). However, the ease of separation makes the polymer-supported CDs more advantageous for use as a heterogeneous catalyst than the pristine CDs. This observation can be explained based on two factors. First, the increase in the

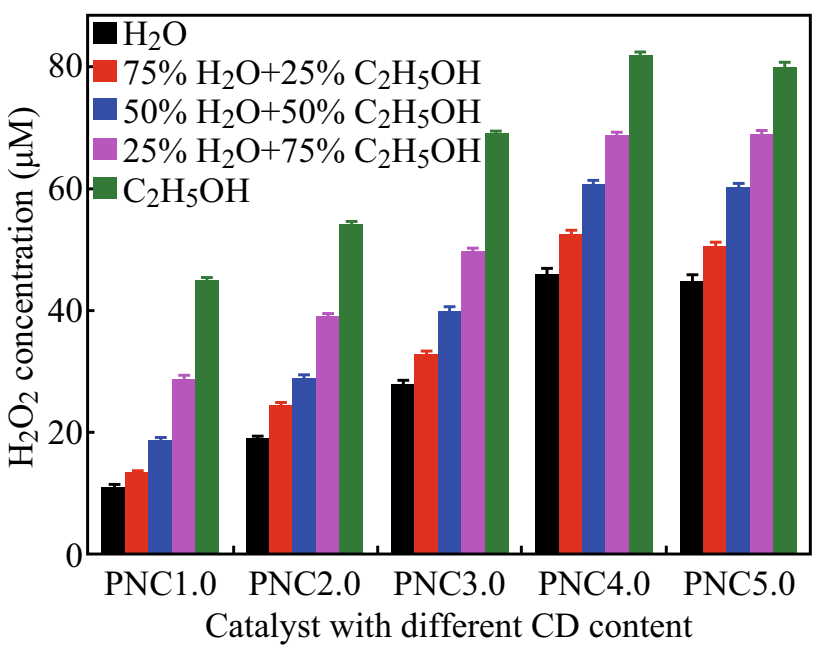

Fig. 7 Effect of $\mathrm{CD}$ loading on $\mathrm{H}_{2} \mathrm{O}_{2}$ production (after $50 \mathrm{~h}$ of reaction)

size of the CDs after incorporation into the polymer matrix (due to intercalation of the polymeric chains in-between the layers of $\mathrm{CD}$, which was confirmed by the increased $d$ spacing) may hamper the light-harvesting ability of the CDs. Secondly, the distribution of the CDs within the polymer matrix is not as uniform as in the solution state. This also contributed to reduction of the photo-catalytic activity of the polymer-supported CDs compared to the pristine CDs.

However, despite these facts, good photo-catalytic activity was observed for the polymer-supported CDs. The reusability of the CD-containing films was evaluated over several cycles. Reusability is an important factor for any catalyst from the green chemistry point of view. Accordingly, a model reaction was performed by using PNC4.0 as the photo-catalyst with a definite amount of reactants for $50 \mathrm{~h}$. After completion of the reaction, the catalyst was recovered, dried, and used again under the same reaction conditions.

Compared to the production of $\mathrm{H}_{2} \mathrm{O}_{2}$ (Fig. 8), there was no statistically significant difference up to the 4 th cycle of use. This indicates the effectiveness of the polymer to hold $\mathrm{CD}$ within the matrix as well as to preserve its catalytic activity. Modification of the WPU/CD system with HE and PAA may contribute in this regard. Such modification results in a highly cross-linked system, which prevents leaching of the CDs from the polymer matrix. However, after the 5th cycle of use, a slight reduction in the yield was observed, though this reduction was not substantial. This may arise due to leaching of some amount of the CDs after several cycles of use, as was confirmed by UV-visible spectroscopy, where the spectrum of the reaction mixture showed a low-intensity peak near $270 \mathrm{~nm}$ (Fig. S5). Thus, the overall results confirm the utility of the polymer- 


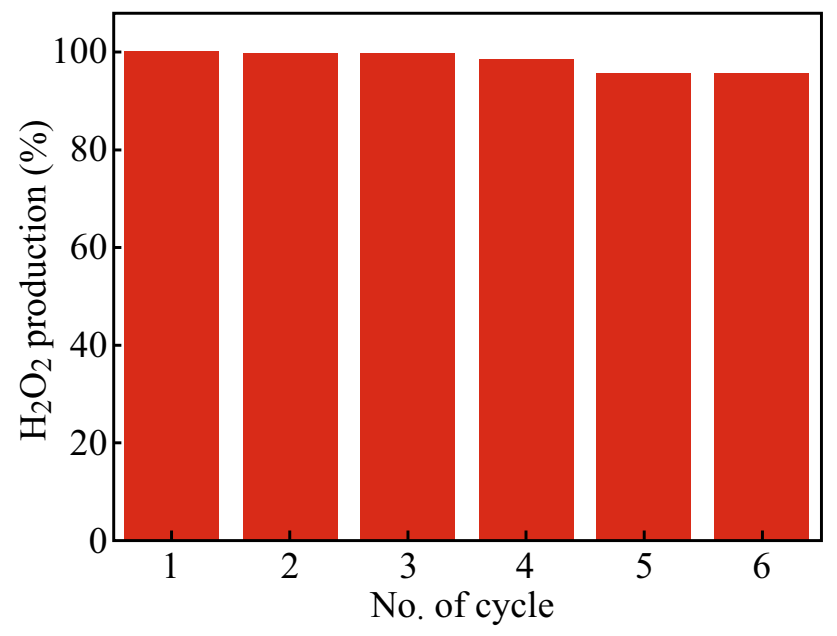

Fig. 8 Reusability of the catalyst (PNC4.0)

supported $\mathrm{CDs}$ as a photo-catalyst for solar-driven production of $\mathrm{H}_{2} \mathrm{O}_{2}$ using $\mathrm{O}_{2}, \mathrm{H}_{2} \mathrm{O}$, and $\mathrm{C}_{2} \mathrm{H}_{5} \mathrm{OH}$ as raw materials.

Bacterial degradation by $P$. aureginosae was evaluated to demonstrate the biodegradability of the catalyst system. Analysis of the bacterial degradation of PNC films revealed adequate biodegradation over the experimental period of seven weeks. The weight loss profiles confirmed that the WPU/CD nanocomposites offer a susceptible surface for bacterial adherence, resulting in high weight loss, which is almost consistent with the $\mathrm{CD}$ loading in the polymer matrix (Fig. 9a). The bacterial growth curves further support this observation (Fig. 9b). An increase in the bacterial population was recorded with time. With an increase in the CD loading, the rate of bacterial growth also increased. This is in contrast with the photo-catalytic activity of the PNCs, where the $\mathrm{H}_{2} \mathrm{O}_{2}$ production decreased when the $\mathrm{CD}$ loading exceeded $4 \mathrm{wt} \%$. This is because $P$. aeruginosa is an organotroph microorganism that utilizes carbon-based materials as a source of food and energy. Hence, a high CD loading favors faster biodegradation. The SEM images (Fig. 9c, d) further confirmed significant bacterial adherence, as well as surface erosion, on the PNC films due to bacterial exposure. Thus, these results indicate the ecofriendly behavior of the catalyst system.

\section{Conclusion}

From the above results, it can be inferred that carbon dots dispersed in a polyurethane matrix can be used as an effective heterogeneous photo-catalyst for solar-driven hydrogen peroxide production. The overall process can be justified as a green practice. It offers the benefits of green chemistry in terms of availability, facile and sustainable preparation, catalyst stability, non-toxicity, recyclability, and biodegradability. The key components, i.e., carbon
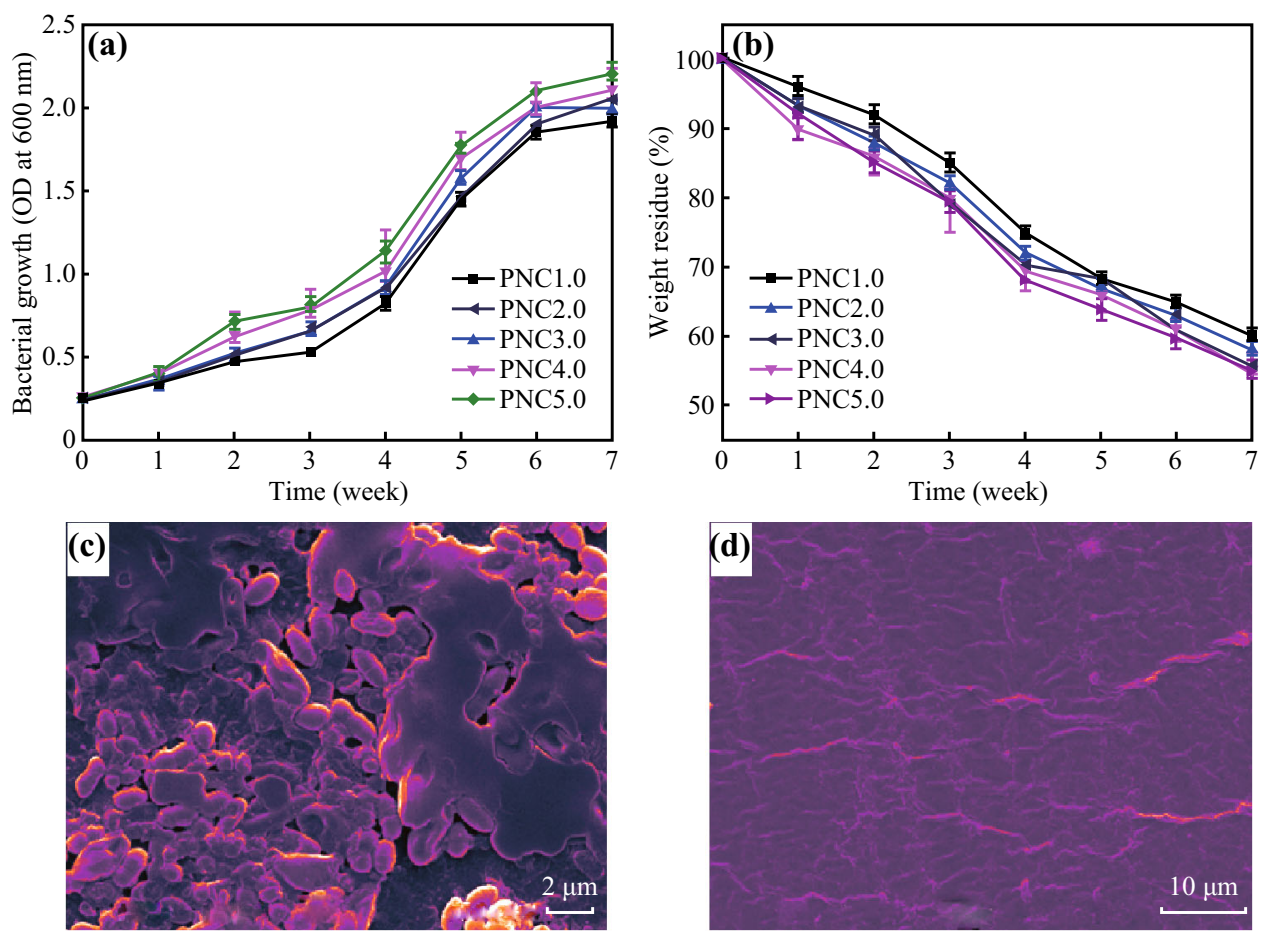

Fig. 9 a Bacterial growth curves of PNCs. b Weight loss curves of PNCs. c SEM image of PNC4.0 after 7 weeks of bacterial exposure. d SEM image of reference film after 7 weeks 
dots, were synthesized using bio-based raw material in a cost-effective, facile process. Further, preparation of the polymeric support, i.e., the polyurethane matrix, was performed in an aqueous medium with a low VOC content. The reusability test confirmed the effectiveness of the catalyst, even after several cycles of use. Compared to other metal-based catalysts that are used for hydrogen peroxide production, the present system offers the benefits of non-toxicity and biodegradability. Further, compared to graphitic carbon nitride, the present system is cost-effective with the additional capability to produce hydrogen peroxide from water under sunlight. This study may pave the way for recognition of polymer-supported carbon dots as heterogeneous photo-catalysts.

Acknowledgements The authors acknowledge DBT (Grant No. BT/ 235/NE/TBP/2011 Dated April 30, 2012), India, for financial support and SAIF, NEHU, Shillong for TEM analysis.

Open Access This article is distributed under the terms of the Creative Commons Attribution 4.0 International License (http://crea tivecommons.org/licenses/by/4.0/), which permits unrestricted use, distribution, and reproduction in any medium, provided you give appropriate credit to the original author(s) and the source, provide a link to the Creative Commons license, and indicate if changes were made.

\section{References}

1. K.A.S. Fernando, S. Sahu, Y. Liu, W.K. Lewis, E.A. Guliants et al., Carbon quantum dots and applications in photocatalytic energy conversion. ACS Appl. Mater. Interfaces 7(16), 8363-8376 (2015). doi:10.1021/acsami.5b00448

2. J. Luo, J.H. Im, M.T. Mayer, M. Schreier, M.K. Nazee-ruddin et al., Water photolysis at $12.3 \%$ efficiency via perovskite photovoltaics and earth-abundant catalysts. Science 345(6204), 1593-1596 (2014). doi:10.1126/science. 1258307

3. T.S. Teets, D.G. Nocera, Photocatalytic hydrogen production. Chem. Commun. 47(33), 9268-9274 (2011). doi:10.1039/ c1cc12390d

4. Y.W. Su, W.H. Lin, Y.J. Hsu, K.H. Wei, Conjugated polymer/nanocrystal nanocomposites for renewable energy applications in photovoltaics and photocatalysis. Small 10(22), 4427-4442 (2014). doi:10.1002/smll.201401508

5. A.E. Sanli, A. Aytac, Response to disselkamp: direct peroxide/ peroxide fuel cell as a novel type fuel cell. Int. J. Hydrogen Energy 36(1), 869-875 (2011). doi:10.1016/j.ijhydene.2010.09. 038

6. Y. Shiraishi, S. Kanazawa, Y. Kofuji, H. Sakamoto, S. Ichikawa, S. Tanaka, T. Hirai, Sunlight-driven hydrogen peroxide production from water and molecular oxygen by metal-free photocatalysts. Angew. Chem. Int. Ed. 53(49), 13454-13459 (2014). doi:10.1002/ange. 201407938

7. F. Sandelin, P. Oinas, T. Salmi, J. Paloniemi, H. Haario, Kinetics of the recovery of active anthraquinones. Ind. Eng. Chem. Res. 45(3), 986-992 (2006). doi:10.1021/ie050593s

8. D. Gudarzi, W. Ratchananusorn, I. Turunen, T. Salmi, M. Heinonen, Preparation and study of Pd catalysts supported on activated carbon cloth (ACC) for direct synthesis of $\mathrm{H}_{2} \mathrm{O}_{2}$ from $\mathrm{H}_{2}$ and $\mathrm{O}_{2}$. Top. Catal. 56(9), 527-539 (2013). doi:10.1007/s11244013-0014-5

9. S. Melada, R. Rioda, F. Menegazzo, F. Pinna, G. Strukul, Direct synthesis of hydrogen peroxide on zirconia-supported catalysts under mild conditions. J. Catal. 239(2), 422-430 (2006). doi:10. 1016/j.jcat.2006.02.014

10. J.K. Edwards, B.E. Solsona, P. Landon, A.F. Carley, A. Herzing, C.J. Kiely, G.J. Hutchings, Direct synthesis of hydrogen peroxide from $\mathrm{H}_{2}$ and $\mathrm{O}_{2}$ using $\mathrm{TiO}_{2}$ supported $\mathrm{Au}-\mathrm{Pd}$ catalysts. J. Catal. 236(1), 69-79 (2005). doi:10.1016/j.jcat.2005.09.015

11. J.C. Pritchard, Q. He, E.N. Ntainjua, M. Piccinini, J.K. Edwards, A.A. Herzing, The effect of catalyst preparation method on the performance of supported $\mathrm{Au}-\mathrm{Pd}$ catalysts for the direct synthesis of hydrogen peroxide. Green Chem. 12(5), 915-921 (2010). doi: $10.1039 / \mathrm{b} 924472 \mathrm{~g}$

12. Y. Isaka, S. Kato, D. Hong, T. Suenobu, Y. Yamadaa, S. Fukuzumi, Bottom-up and top-down methods to improve catalytic reactivity for photocatalytic production of hydrogen peroxide using a Ru-complex and water oxidation catalysts. J. Mater. Chem. A 3(23), 12404-12412 (2015). doi:10.1039/C5TA02446C

13. S. Kato, J. Jung, T. Suenobu, S. Fukuzumi, Production of hydrogen peroxide as a sustainable solar fuel from water and dioxygen. Energy Environ. Sci. 6(12), 3756-3764 (2013). doi:10. 1039/c3ee42815j

14. C. Kormann, D.W. Bahnemann, M.R. Hoffmann, Photocatalytic production of hydrogen peroxides and organic peroxides in aqueous suspensions of titanium dioxide, zinc oxide, and desert sand. Environ. Sci. Technol. 22(7), 798-806 (1988). doi:10.1021/ es00172a009

15. R. Cai, Y. Kubota, A. Fujishima, Effect of copper ions on the formation of hydrogen peroxide from photocatalytic titanium dioxide particles. J. Catal. 219(1), 214-218 (2003). doi:10.1016/ S0021-9517(03)00197-0

16. H. Goto, Y. Hanada, T. Ohno, M. Matsumura, Quantitative analysis of superoxide ion and hydrogen peroxide produced from molecular oxygen on photoirradiated $\mathrm{TiO}_{2}$ Particles. J. Catal. 225(1), 223-229 (2004). doi:10.1016/j.jcat.2004.04.001

17. V. Maurino, C. Minero, G. Mariella, E. Pelizzetti, Sustained production of $\mathrm{H}_{2} \mathrm{O}_{2}$ on irradiated $\mathrm{TiO}_{2}$-fluoride systems. Chem. Commun. 36(33), 2627-2629 (2005). doi:10.1039/b418789j

18. T. Hirakawa, Y. Nosaka, Selective production of superoxide ions and hydrogen peroxide over nitrogen-and sulfur-doped $\mathrm{TiO}_{2}$ photocatalysts with visible light in aqueous suspension systems. J. Phys. Chem. C 112(40), 15818-15823 (2008). doi:10.1021/ jp8055015

19. M. Teranishi, S. Naya, H. Tada, In situ liquid phase synthesis of hydrogen peroxide from molecular oxygen using gold nanoparticle-loaded titanium (IV) dioxide photocatalyst. J. Am. Chem. Soc. 132(23), 7850-7851 (2010). doi:10.1021/ja102651g

20. D. Tsukamoto, A. Shiro, Y. Shiraishi, Y. Sugano, S. Ichikawa, S. Tanaka, Platinum nanoparticles supported on anatase titanium dioxide as highly active catalysts for aerobic oxidation under visible light irradiation. ACS Catal. 2(2), 599-603 (2012). doi:10. 1021/cs300407e

21. Y. Shiraishi, S. Kanazawa, Y. Sugano, D. Tsukamoto, H. Sakamoto, S. Ichikawa, T. Hirai, Highly selective production of hydrogen peroxide on graphitic carbon nitride $\left(\mathrm{g}-\mathrm{C}_{3} \mathrm{~N}_{4}\right)$ photocatalyst activated by visible light. ACS Catal. 4(3), 774-780 (2014). doi:10.1021/cs401208c

22. V.D. Dao, P. Kim, S. Baek, L.L. Larina, K. Yong, R. Ryoo, Facile synthesis of carbon dot-Au nanoraspberries and their application as high-performance counter electrodes in quantum dot-sensitized solar cells. Carbon 96, 139-144 (2016). doi:10. 1016/j.carbon.2015.09.023

23. Z. Yang, Z. Li, M. Xu, Y. Ma, J. Zhang et al., Controllable synthesis of fluorescent carbon dots and their detection 
application as nanoprobes. Nano-Micro Lett. 5(4), 247-259 (2013). doi:10.5101/nml.v5i4.p247-259

24. W. Kwon, S. Do, J. Lee, S. Hwang, J.K. Kim, S.W. Rhee, Freestanding luminescent films of nitrogen-rich carbon nanodots toward large scale phosphor based white light emitting devices. Chem. Mater. 25(9), 1893-1899 (2013). doi:10.1021/cm400517g

25. Z. Song, F. Quan, Y. Xu, M. Liu, L. Cui, J. Liu, Multifunctional $\mathrm{N}, \mathrm{S}$ co-doped carbon quantum dots with $\mathrm{pH}-$ and thermo-dependent switchable fluorescent properties and highly selective detection of glutathione. Carbon 104, 169-178 (2016). doi:10. 1016/j.carbon.2016.04.003

26. S. Sahu, Y. Liu, P. Wang, C.E. Bunker, K.A.S. Fernando et al., Visible-light photoconversion of carbon dioxide into organic acids in an aqueous solution of carbon dots. Langmuir $\mathbf{3 0}(28)$, 8631-8636 (2014). doi:10.1021/la5010209

27. B. De, B. Voit, N. Karak, Carbon dot reduced $\mathrm{Cu}_{2} \mathrm{O}$ nanohybrid/ hyperbranched epoxy nanocomposite: mechanical, thermal and photocatalytic activity. RSC Adv. 4(102), 58453-58459 (2014). doi:10.1039/C4RA11120F

28. D. Mosconi, D. Mazzier, S. Silvestrini, A. Privitera, C. Marega, L. Franco, Synthesis and photochemical applications of processable polymers enclosing photoluminescent carbon quantum dots. ACS Nano 9(4), 4156-4164 (2015). doi:10.1021/acsnano. $5 b 00319$

29. S. Barua, G. Dutta, N. Karak, Glycerol based tough hyperbranched epoxy: synthesis, statistical optimization and property evaluation. Chem. Eng. Sci. 95(3), 138-147 (2013). doi:10.1016/ j.ces.2013.03.026

30. S. Gogoi, N. Karak, Bio-based high-performance waterborne hyperbranched polyurethane thermoset. Polym. Adv. Technol. 26(6), 589-596 (2015). doi:10.1002/pat.3490

31. S. Gogoi, M. Kumar, B.B. Mandal, N. Karak, High performance luminescent thermosetting waterborne hyperbranched polyurethane/carbon quantum dot nanocomposite with in vitro cytocompatibility. Compos. Sci. Technol. 118, 39-46 (2015). doi:10.1016/j.compscitech.2015.08.010

32. C. Zhu, S. Guo, Y. Fang, S. Dong, Reducing sugar: new functional molecules for the green synthesis of graphene nanosheets. ACS Nano 4(4), 2429-3247 (2010). doi:10.1021/nn1002387

33. B. De, N. Karak, A green and facile approach for the synthesis of water soluble fluorescent carbon dots from banana juice. RSC Adv. 3(22), 8286-8290 (2013). doi:10.1039/c3ra00088e

34. S. Pramanik, R. Konwarh, K. Sagar, B.K. Konwar, N. Karak, Bio-degradable vegetable oil based hyperbranched poly(ester amide) as an advanced surface coating material. Prog. Org. Coat. 76(4), 689-697 (2013). doi:10.1016/j.porgcoat.2012.12.011

35. L. Zhu, Y. Yin, C.F. Wang, S. Chen, Plant leaf-derived fluorescent carbon dots for sensing, patterning and coding. J. Mater. Chem. C 1(32), 4925-4932 (2013). doi:10.1039/c3tc30701h

36. S. Sahu, B. Behera, T.K. Maiti, S. Mohapatra, Simple one-step synthesis of highly luminescent carbon dots from orange juice: application as excellent bio-imaging agents. Chem. Commun. 48(70), 8835-8837 (2012). doi:10.1039/c2cc33796g

37. L. Cao, S. Sahu, P. Anilkumar, C.E. Bunker, J. Xu, K.A.S. Fernando et al., Carbon nanoparticles as visible light photocatalysts for efficient $\mathrm{CO}_{2}$ conversion and beyond. J. Am. Chem. Soc. 133(13), 4754-4757 (2011). doi:10.1021/ja200804h

38. J. Wang, S. Sahu, S.K. Sonkar, K.N. Tackett, K.W. Sun et al., Versatility with carbon dots-from overcooked BBQ to brightly fluorescent agents and photocatalysts. RSC Adv. 3(36), 15604-15607 (2013). doi:10.1039/c3ra42302f

39. Y. Yang, W. Kong, H. Li, J. Liu, M. Yang et al., Fluorescent $\mathrm{N}$-doped carbon dots as in vitro and in vivo nanothermometer. ACS Appl. Mater. Interfaces 7(49), 27324-27330 (2015). doi:10. 1021/acsami.5b08782 